REGARDS

SUR LEECONOMIE ALLEMAND

BULLETIN ECONOMIQUE DU CIRAC
Regards sur l'économie allemande

Bulletin économique du CIRAC

$77 \mid 2006$

Varia

\title{
Démographie : l'Allemagne est une société métissée
}

Isabelle Bourgeois

\section{CpenEdition}

Journals

Édition électronique

URL : http://journals.openedition.org/rea/803

DOI : $10.4000 /$ rea. 803

ISBN : 978-2-8218-0850-8

ISSN : 1965-0787

Éditeur

CIRAC

Édition imprimée

Date de publication : 1 juillet 2006

Pagination : 38-39

ISSN : 1156-8992

Référence électronique

Isabelle Bourgeois, « Démographie : l'Allemagne est une société métissée », Regards sur l'économie allemande [En ligne], 77 | juillet 2006, document 2, mis en ligne le 01 juillet 2008, consulté le 10 décembre 2020. URL : http://journals.openedition.org/rea/803; DOI : https://doi.org/10.4000/rea.803

Ce document a été généré automatiquement le 10 décembre 2020.

(C) CIRAC 


\title{
Démographie : l'Allemagne est une société métissée
}

\author{
Isabelle Bourgeois
}

\section{9 \% de la population est étrangère ou issue de l'immigration...}

1 La Mannschaft reflète très exactement la composition de la population de l'Allemagne : 5 des 25 footballeurs sélectionnés sont d'origine étrangère ou issus de l'immigration, soit $20 \%$. Un cinquième des habitants de l'Allemagne (19\% précisément, soit 15,3 millions) est de nationalité étrangère (7,3 millions) ou comprend des Allemands rapatriés ou issus de l'immigration (8 millions). Ce dernier groupe n'était pas pris en compte jusqu'à présent : il comprend toutes les personnes de nationalité allemande depuis une, deux ou trois générations, quelle que soit leur origine géographique ou leur nationalité d'origine.

\section{... selon le Mikrozensus 2005 de Destatis}

2 Voilà ce que révèle l'édition 2005 du Mikrozensus présentée début juin par Destatis. Ce 'micro-recensement' est effectué tous les ans depuis 1957. Aujourd'hui, l'échantillon représentatif comprend 830000 personnes (390 000 foyers), soit $1 \%$ de la population. Depuis 2005, les sondages s'effectuent tout au long de l'année afin de livrer une photographie plus fine de l'évolution de la société. De nouveaux indicateurs sont également pris en considération - dont le thème «migration et intégration » dès l'édition actuelle. 


\section{8 millions d'Allemands sont issus de l'immigration}

3 On y apprend ainsi que la part des ressortissants étrangers est inférieure à celle des Allemands 'intégrés' au fil des générations. On l'ignorait jusqu'ici. Dans le premier groupe domine la première génération d'immigrés (5,6 millions de personnes), leurs enfants nés en Allemagne étant 1,6 million. La composition du second groupe, plus complexe, reflète l'histoire allemande, ainsi que la récente évolution du droit de la nationalité. Il comprend : 3,5 millions de personnes naturalisées (intégration classique avec abandon de la nationalité d'origine ou double nationalité), 1,8 million d'Allemands rapatriés après le 01-08-1999 (Spätaussiedler; ceux qui ont immigré avant cette date sont recensés comme naturalisés) et 2,7 millions d'Allemands de seconde génération. Cette dernière catégorie inclut 1,2 million de personnes nées en Allemagne et qui ont obtenu la nationalité allemande en vertu du nouveau régime de droit du sol, ainsi que 1,5 million d'Allemands dont l'un des parents est de nationalité étrangère, rapatrié ou a été naturalisé.

\section{Le tiers des moins de 15 ans est d'origine / de nationalité étrangère}

4 La prise en compte plus fine de l'historique des migrations dans la population allemande permet de mieux comprendre l'évolution démographique. Près du tiers des moins de 15 ans, par exemple, est issu de l'immigration ou de nationalité étrangère. Ce sont leurs parents qui assurent pour l'essentiel le renouvellement des générations dans la mesure où le recul de la natalité est l'apanage des Allemands de souche (67,1 millions). Mais chez les premiers, le taux de fertilité tend à baisser du fait de l'intégration croissante de cette population, en Allemagne comme dans le reste de l'Europe.

\section{On ne se marie plus forcément pour fonder un foyer...}

Depuis 1991, la part des foyers où vivent au moins deux générations est tombée de $30 \%$ à $32 \%$ seulement. Celle des foyers avec des enfants mineurs (8,9 millions) s'est réduite de $27 \%$ à $23 \%$. Reflet de la faible natalité allemande, ces foyers n'élèvent plus en moyenne que 1,61 enfant chacun (1,65 en 1996). Fait intéressant, outre-Rhin aussi, le mariage est en perte de vitesse, bien qu'il demeure souvent le passage obligé à la naissance d'un enfant. Ainsi, sur un total de 12,6 millions de familles avec enfants mineurs ou majeurs, la part des couples mariés est passée de $79 \%$ en 1996 à aujourd'hui $73 \%$. Les couples de parents non mariés sont aujourd'hui 2,4 millions ( $6 \%$ contre $4 \%$ auparavant). La part des familles monoparentales s'est accrue de 17 à $21 \%$.

\section{... surtout à l'est}

6 Les modes de vie familiaux diffèrent entre l'est et l'ouest : alors que $66 \%$ des enfants ouest-allemands vivent dans une famille traditionnelle (parents mariés, au moins un frère ou une sœur), ils ne sont que $44 \%$ à l'est. Dans les nouveaux Länder, plus d'enfants naissent et grandissent hors mariage : la part des familles (parents et enfants) 
dans l'ensemble des couples vivant en union libre y oscille depuis des années entre $45 \%$ et $48 \%$. Cette part n'est que de $26 \%$ à l'ouest, mais en progression ( $21 \%$ en 1996), suivant la hausse de la part des couples vivant en concubinage (+37\% depuis 1996).

\section{$22 \%$ de foyers de seniors}

7 Cela étant, la structure des foyers (30,7 millions à l'ouest et 8,4 millions à l'est) est largement harmonisée : les single sont respectivement $37 \%$ et $40 \%$, les couples $34 \%$ et $35 \%$, et les foyers de trois personnes ou plus sont $29 \%$ et $25 \%$. La plus forte part des singles à l'est est imputable à la seule ville de Berlin, où on compte $51 \%$ de foyers à une personne. Car la vie de célibataire est avant tout un phénomène urbain, réservé aux grandes agglomérations: Hanovre mène avec $55 \%$, suivie par Francfort/Main (53\%), Munich (52\%), Hambourg ( $49 \%$ ) et Brême (48\%). Aucune différence notoire par contre entre anciens et nouveaux Länder en ce qui concerne le vieillissement démographique : un tiers des foyers se compose d'au moins un senior (plus de 65 ans). $22 \%$ des foyers sont composés exclusivement de seniors, qu'il vivent seuls (59\%) ou en couple (41\%).

\section{Un métissage en progression}

8 L'évolution de la nationalité des foyers, quelle qu'en soit la taille, révèle une tendance au métissage : 90 \% d'entre eux sont purement allemands, mais ils étaient encore $93 \%$ en 1991. Autrement dit: dans $10 \%$ des foyers vit au moins une personne de nationalité étrangère. La part des foyers composés exclusivement d'étrangers n'est passée que de $5 \%$ à $6 \%$. Celle qui a comparativement le plus augmenté (de $2 \%$ à $4 \%$ ) est celle des foyers mixtes. Ces proportions sont comparables si on ne considère que les couples en général (21,4 millions au total). En revanche, elles varient selon qu'ils sont mariés ou non. Parmi les couples mariés (18,9 millions), $88 \%$ unissent deux conjoints de nationalité allemande, $6 \%$ deux conjoints de nationalité étrangère (le plus souvent la même), et $6 \%$ sont des couples mixtes. Les couples non mariés ( 2,4 millions) sont un peu moins métissés : $90 \%$ sont allemands, $8 \%$ étrangers, et seulement $2 \%$ sont mixtes.

\section{Les Allemands épousent des Polonaises, les Allemandes, des Turcs}

Quelles sont les préférences géographiques des Allemands quand ils choisissent leur conjoint ou concubin? Les prédilections des hommes et des femmes se distinguent franchement. Lorsqu'ils prennent épouse, les Allemands préfèrent les Polonaises (11 \%), les Russes (10\%) et les Turques ( $9 \%)$; lorsqu'ils vivent en concubinage, ils choisissent plutôt les Autrichiennes (12\%), les Polonaises ( $9 \%$ ) et les Italiennes ( $8 \%)$. Les Allemandes, elles, convolent de préférence avec des Turcs (17\%), des Italiens (12\%) et des Autrichiens ( $7 \%$ ). Mais dans le rôle de concubins, leur faveur va de loin aux Italiens (20\%), ensuite seulement aux Turcs (11\%) et aux Autrichiens (8\%).

Destatis publie ces chiffres sans les commenter. Mais ces choix d'union peuvent s'expliquer. Si on excepte les qualités prêtées aux diverses nationalités dans l'imaginaire collectif (la 'belle Polonaise', le rôle de latin lover par excellence dévolu à l'Italien) et la proximité culturelle évidente avec les Autrichiens, ces données, loin de 
traduire les parts respectives des différentes nationalités dans la population résidante (les Turcs sont près de 2 millions, les Autrichiens, à peine 175 000), reflètent bien plutôt l'historique des flux migratoires en Europe. Et elles attestent d'un large métissage culturel au fil des générations. La communauté polonaise est la plus ancienne, venue s'installer dans les bassins houillers dès le milieu du XIXe siècle ; l'élargissement de l'UE a renoué ces liens dans la jeune génération. La communauté italienne est venue au tout début des années 1950, apportant sa contribution au "miracle économique » qui permettra aux Allemands d'aller passer leurs congés payés en Italie; il en reste un net métissage gastronomique (le 'plat national' allemand est aujourd'hui... la pizza). La communauté turque, arrivée à la même époque, a participé elle aussi au redémarrage de l'économie mais, concentrée dans quelques agglomérations, elle s'est moins assimilée. Quant à l'immigration russe, elle remonte à la perestroïka et peut se lire comme la contribution indirecte de l'ex-RDA au métissage de la société allemande d'aujourd'hui...

INDEX

Mots-clés : démographie, étranger, immigration, société 